\title{
The effects of concurrent training (aerobic- resistance) and milk consumption on some markers of bone mineral density in women with osteoporosis
}

\author{
Hamid Arazi $^{1^{*}}$ D, Mahbobeh Samadpour ${ }^{2}$ and Ehsan Eghbali ${ }^{3}$
}

\begin{abstract}
Background: Osteoporosis is a skeletal metabolic disorder characterized by low bone mineral density (BMD) and reduced bone strength leading to higher bone fractures risk. The present study attempted to investigate the effects of concurrent training (aerobic-resistance) and milk consumption on some markers of BMD in women with osteoporosis.

Methods: For this purpose, forty women diagnosed with osteoporosis within an age range of 30-45 years were divided into four groups of ten including concurrent training-milk, concurrent training, milk consumption and control group. The concurrent exercises were performed in ten weeks with three sessions in each week including aerobic training (running at $55-75 \%$ of maximum heart rate) and resistance training (4 move in a circle performed two times with 10 repetition maximum (RM)). Milk consumption was two times of $250 \mathrm{ml}$ per day in ten weeks. Before and after treatment, BMDs in the hip and lumbar spine area were estimated with Dual-energy X-ray absorptiometry (DEXA) device and $5 \mathrm{cc}$ blood was taken from a vein in the arm to determine the blood levels of 25 -hydroxyvitamin $\mathrm{D}(25 \mathrm{OH}-$ D) and alkaline phosphatase (ALP).

Results: Based on the results, blood levels $25 \mathrm{OH}$-D and ALP significantly increased in concurrent training-milk, concurrent training and milk group with higher increase in concurrent training-milk group $(P<0.05)$. Furthermore, the right and left hip BMD in concurrent training-milk and concurrent training groups increased significantly with higher increase in concurrent training-milk group $(p<0.05)$. Also, lumbar spine BMD increased significantly in concurrent training-milk and concurrent training $(p<0.05)$.

Conclusions: It seems that combination of concurrent training and milk consumption has more efficient impacts on the BMD of young women diagnosed with osteoporosis compared to the milk or concurrent training groups alone. This treatment can be used as an effective way to improve BMD in young women with diagnosed osteoporosis.
\end{abstract}

Keywords: Osteoporosis, Concurrent training, Milk, 25-Hydroxyvitamin D, Alkaline phosphatase

\section{Background}

Osteoporosis is a skeletal systemic and metabolic disease characterized by low bone density and high fracture leading to lower bone strength and in turn, higher risk of fracture [1, 2]. Osteoporosis is recognized as the fourth dangerous disease after heart disease, cancer and diabetes by World Health Organization (WHO) [1, 2].

\footnotetext{
* Correspondence: hamidarazi@yahoo.com

${ }^{1}$ Department of Exercise Physiology, Faculty of Sport Sciences, University of Guilan, Rasht, Iran

Full list of author information is available at the end of the article
}

Development and increase of osteoporosis can be attributed to lifestyle and dimorphic factors [3]. Maintaining a favorable nutrition status is a major contributor to the prevention of osteoporosis. One of the main food groups is dairy foods, one of the richest sources of nutrients, such as protein, calcium, magnesium and B vitamins, which helps expanding bone health [4]. Many believe that milk is a very important nutritional material for increasing bone mass. It is one of the main sources of calcium and other elements necessary for the body including vitamin $\mathrm{D}$, protein, potassium and phosphorus

(c) The Author(s). 2018 Open Access This article is distributed under the terms of the Creative Commons Attribution 4.0 International License (http://creativecommons.org/licenses/by/4.0/), which permits unrestricted use, distribution, and reproduction in any medium, provided you give appropriate credit to the original author(s) and the source, provide a link to the Creative Commons license, and indicate if changes were made. The Creative Commons Public Domain Dedication waiver (http://creativecommons.org/publicdomain/zero/1.0/) applies to the data made available in this article, unless otherwise stated. 
[5]. Calcium is a vital element of BMD which decreases the risk of bone fractures in people diagnosed with osteoporosis [6]. Furthermore, dairy foods can increase lean body mass and fat oxidation [7]. Among the indicators of BMD, ALP and serum levels of $25 \mathrm{OH}-\mathrm{D}$ have an important role in BMD. As a biomarker of bone, ALP is an enzyme which is found in various tissues throughout the body including the liver, bone, kidney, intestine and placenta. It is mainly produced in liver and bone marrow. In bone diseases, ALP levels increase due to osteoblast activity and the amount varies depending upon age and sex [8]. Vitamin D is present in the diet as cholecalciferol. It is the only vitamin that needs a certain amount of direct sunlight besides daily diet. Vitamin D is stored in several parts of the body such as the skin and stimulates calcium absorption from the small intestine and increases calcium reabsorption from the stems and distal renal tubules [6-8].

Regular physical activity decreases the risk of health problems including obesity, heart disease, stroke, colon cancer, diabetes and osteoporosis [9]. It is considered as a preventive approach to reduce the risk of osteoporosis, falls and fractures. Physical activities such as gymnastics and weightlifting, which leads to putting a high load on the body and producing strong forces of gravity, have higher osteogenic impacts compared to activities such as swimming and cycling which consume a lot of energy [10]. Evidence suggests that greater load has more beneficial effect compared to repeated load [11].

Physical activity an important role in the development and maintenance of BMD [12]. Physical activities improve bone strength through creation of intermittent mechanical stress on the skeletal system. Research has shown that the type, intensity and duration of exercise have an influence on the BMD. So, physical activity plays an important role in the development and maintenance of bone mass and density. Peak of the force is an important and decisive factor in the analysis of mechanical load to the bone $[13,14]$.

Osteogenic response mechanism to load suggests that a long time physical activity has anabolic effects on the bones and improve bone density and strength. Results of the experimental research showed that a long time physical activity course with high-speed traction and high peak force had greater impact on bone osteogenic response compared to high repetition exercises with low power $[15,16]$. Studies have shown that training for a long time (6-36 months) has positive effects on increasing bone density while training for a short time (less than 6 months) did not show similar results $[15,16]$.

Marques et al. [17] showed that eight months of resistance training may be more effective than aerobic exercise and can produce favorable changes in BMD and muscle strength. Also, the result of Hawley et al. [18] showed that resistance exercise is effective in increasing BMD in healthy young men, but has no effect on BMD in the women. Age appropriate exercises can cause balance, flexibility, coordination and muscle growth, because the muscles support the bones and also blood supply to the bones and joints increases and prevent fall and fracture.

According to the reviewed literature related to diet and exercises, it is not yet clear whether these factors can separately increase the BMD in young women with osteoporosis or they can do that more efficiently when combined together? Therefore, this study aimed at investigating the benefits of concurrent exercises including aerobic and resistance exercises (the American College of Sports Medicine in recent years compared this model to aerobic or resistance exercises alone) accompanied with milk consumption in young women with osteoporosis compared to applying them separately.

\section{Methods}

The participants in this study included 40 Iranian young women diagnosed with osteoporosis within the age range of 30-45 years. Participants declared their preparation on a voluntary basis, after announcements in medical offices and associated laboratories belong to city of Bandar-e Anzali. The criteria for inclusion were: lack of diseases such as thyroid, diabetes, no use of certain drugs (drugs affecting BMD i.e., corticosteroids, ...), sedentary lifestyle (lack of regular exercise) and not using low-fat dairy (milk, yogurt, cheese) as a source of vitamin D. Participants in the study used usual diets and received little sunlight due to their geographical and religious conditions and the type of clothing worn. Dietary intake was assessed by three-day dietary record (calcium intake was 300-650 mg per day). In addition, subjects only had daily physical activity (activities related to daily living that may include house cleaning, grocery shopping, laundry etc., but not specifically games/sports and other forms of physical activity). The University Ethics Committee approved the terms of the project.

Among the 150 persons visiting densitometry centers, 40 persons were eligible to participate in this study; they were randomly divided into four groups of ten including concurrent training-milk, concurrent training, milk consumption and control group. After making the participants aware of the research goals and procedure, they were asked to fill the consent form. Then, BMD of the lumbar spine and hip of the participants were taken by the technician. Two to three days before the start of training, with regard to the fifth day of the menstrual cycle (8-10 h fasting), blood test was taken to determine 25OH-D and ALP for the four groups (concurrent training-milk, concurrent training, milk consumption and control). The starts of training and taking blood test were 
adjusted with regard to the fifth day of the menstrual cycle for each woman. The pre and post tests were conducted before and after two and a half months of concurrent training and milk consumption for different groups.

The participants in the milk consumption and concurrent training-milk consumed $500 \mathrm{ml}$ of daily milk for 10 weeks [14]. The milk consumption and training group and the milk consumption group drank milk immediately $(250 \mathrm{ml})$ and one hour after training $(250 \mathrm{ml})$. Commercial low-fat milk was used in this study. The components of this milk per $250 \mathrm{~mL}$ are as follows: energy, $113 \mathrm{kcal}$; protein, $8.0 \mathrm{~g}$; carbohydrate, $11.5 \mathrm{~g}$; fat, $3.8 \mathrm{~g}$; calcium, $338 \mathrm{mg}$; zinc, $1.0 \mathrm{mg}$; iodine, $33 \mu \mathrm{g}$; vitamin A, $400 \mu$ g; vitamin D3, $6.25 \mu \mathrm{g}$; vitamin B2, $0.33 \mathrm{mg}$; and vitamin B12, $1.30 \mu \mathrm{g}$.

After measuring the height and weight, body mass index (BMI) was calculated by dividing weight $(\mathrm{kg})$ by the square of height $(\mathrm{m})$. Also, to measure waist to hip ratio (WHR), the waist circumference was divided to hip circumference. The researcher used Jackson \& Pollock method to measure body fat percentage and subcutaneous fat thickness of three points of the body including the triceps, supraspinale and thigh and the body density was determined for each individual [19]. Then, using Brozek equation, body fat percentage was measured for each individual [20]. Skin fold thickness was obtained using calipers calibrated (Lafayette model o1127, USA) to an accuracy of $1 \mathrm{~mm}$. All the measurement was done on the right side of the body in three times and the average number was used as the main number.

\section{Training protocol}

The concurrent training (aerobic-resistance) was performed by groups in 10 weeks and 3 sessions each weak (each session lasted approximately $90-110 \mathrm{~min}$ ). At the beginning, the training started with stretching and warm-up exercises (10-15 min) and continued with aerobic training (25-40 min), resistance training (working with different devices (25-40 min)) and cool-down/relaxation exercises (10-15 min). Aerobic training included 3 sets of $5 \mathrm{~min}$, running with $55-75 \%$ of heart rate maximum (HRmax) of the target (heart rate during exercise was continuously monitored by heart rate monitors (Polar, AXN500)) and exercise intensity gradually increased for 5\% HRmax and 3-5 min in every two weeks (rest period of approximately $3 \mathrm{~min}$ between each set). Resistance training involved performing 2 sets of bench press, leg extension, wide grip pull-down and leg curls which were circular with 10RM (subjects exercised on variable resistance machines). To minimize fatigue, the exercises for the upper/lower parts of the body were performed in a non-consecutive way, with a rest period of approximately 1-2 min between each set. Training intensity was gradually increased in every two weeks for new 10RM (Fig. 1).

\section{Blood analysis, 250H-D and ALP}

The participants were fasting $8-10 \mathrm{~h}$ before the experiment. Measuring blood levels of 25OH-D and serum ALP was conducted for $48 \mathrm{~h}$ before and after training for $5 \mathrm{cc}$ from the brachial vein in sitting position (initial measurements were adjusted with regard to the fifth day of the menstrual cycle for each woman). Finally, after being transported to the laboratory and centrifuged at $3000 \mathrm{rpm}$, the units of $25 \mathrm{OH}-\mathrm{D}$ and ALP levels were determined. Thus, the $25 \mathrm{OH}-\mathrm{D}$ was measured with $\mathrm{CV} 2$ to $3 \%$ with Elisa device (Danna model) and American parts, assembled in Iran and ALP with Hitachi device (911, Japan) with a sensitivity of $3 \%$. The Institute of Medicine (IOM) has defined "deficiency" as a $25 \mathrm{OH}-\mathrm{D}$ value below $12 \mathrm{ng} / \mathrm{mL}(30 \mathrm{nmol} / \mathrm{L})$ and "sufficiency" as values above $20 \mathrm{ng} / \mathrm{mL}(50 \mathrm{nmol} / \mathrm{L})$ [21].

\section{Measurement of BMD}

BMD was measured at two areas of the lumbar spine (L2-L4) and hip by DXA device (UNIGAMMA PLUS AC $230 \mathrm{~V} 50 / 60 \mathrm{~Hz} 400 \mathrm{w}$, USA). In this analysis, BMD at the lumbar spine was estimated from L2 to L4. The hip BMD (femoral neck) used in the analysis was estimated from the right and left side. The WHO defines osteopenia and osteoporosis based on BMD: osteopenia is BMD less than -1 and more than -2.5 standard deviations in relation to the mean BMD of young adults, and osteoporosis is BMD less than -2.5 standard deviations in relation to the mean BMD of young adults [22].

\section{Statistical analysis}

Mean and standard deviation of data were calculated using descriptive statistics. The Shapiro-Wilk test was used to check for normality test of data distribution and one-way ANOVA in the baseline analysis were used. One-way Analysis of Covariance (ANCOVA) was used to compare post-tests among the groups, because some of the pre-tests were different between the 4 groups, the effects of pre-tests were adjusted through ANCOVA. In the event of a significant F- ratio, LSD post-hoc tests were used for pairwise comparisons. Paired t-test was used to compare intergroup changes. The analyses were performed using SPSS 20 and Excel 2010. The $P \leq 0.05$ was considered as the level of significance.

\section{Results}

Basic features and indicators of BMD in subjects are shown in Table 1 . In baseline, there were no statistical differences in age, height, weight, BMI, WHR, body fat and ALP ( $>>0.05)$. However, 25OH-D, hip and lumbar spine BMD showed significant differences $(p<0.05)$ (Table 1). The effect of pre-tests adjusted through ANCOVA. 


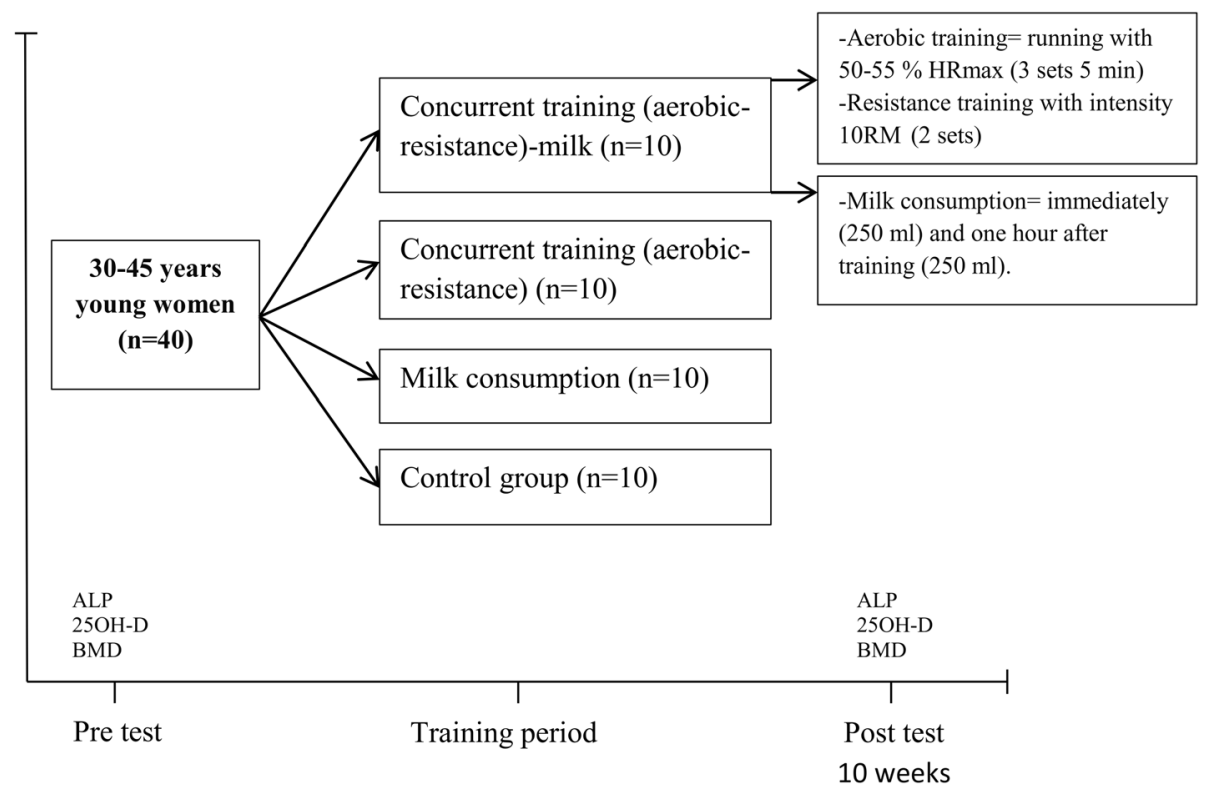

Fig. 1 Study design. Alkaline phosphatase (ALP); 25-hydroxyvitamin D (25OH-D); bone mineral density (BMD)

Paired t test results showed that changes in $25 \mathrm{OH}-\mathrm{D}$ and ALP of concurrent training-milk, concurrent training and milk consumer group were significant $(25 \mathrm{OH}-\mathrm{D}$ : $p<0.001, p<0.001, p=0.03$; ALP: $p<0.001, p<0.001, p$ $=0.01$; respectively). Also, the changes in the hip BMD values (right and left) and lumbar spine BMD in concurrent training-milk and concurrent training were significant (right: $p<0.001, \mathrm{p}=0.01$; left: $p<0.001, p<0.001$; lumbar spine: $p=0.02, p<0.001$; respectively), while there was no significant change in the milk consumer group ( $p=0.15, p=0.09, p=0.10$; respectively) (Fig. 2).

As demonstrated in Table 2, results of ANCOVA and LSD post-hoc test showed that there were significant differences in 25OH-D, right hip and lumbar spine BMD in the concurrent training-milk group compared to concurrent training, milk consumers and control groups (25OH-D: $p=0.04, p=0.009, p<0.001$; right hip: $p=$ $0.001, p=0.001, \mathrm{p}<0.001$; lumbar spine: $p=0.01, p<$ $0.001, p<0.001$; respectively). Also, $25 \mathrm{OH}-\mathrm{D}$ changes in concurrent training group was significant compared to control group while there was not significant compared to the milk consumer group $(p=0.01, p=0.49$; respectively). Furthermore, ALP changes in concurrent training-milk group was significant compared to control groups $(p=0.03)$, while there was not significant compared to the concurrent training and milk consumers group ( $p=0.73, p=0.14$; respectively). Changes in BMD of the left hip in concurrent training-milk group was

Table 1 Demographic characteristics and some indicators of BMD at baseline in the subject groups

\begin{tabular}{|c|c|c|c|c|c|}
\hline \multirow[t]{2}{*}{ Characteristic } & \multicolumn{5}{|l|}{ Mean \pm SD } \\
\hline & $\mathrm{CT}+\mathrm{MC}$ & $C T$ & $M C$ & C & $P$ \\
\hline Age (years) & $38.30 \pm 4.76$ & $37.30 \pm 3.30$ & $37.80 \pm 4.75$ & $38.80 \pm 4.23$ & 0.49 \\
\hline Height (cm) & $162.34 \pm 7.12$ & $163.56 \pm 5.48$ & $163.85 \pm 6.32$ & $161.34 \pm 6.21$ & 0.32 \\
\hline Weight (kg) & $63.95 \pm 5.83$ & $64.20 \pm 7.91$ & $62.00 \pm 6.27$ & $64.50 \pm 9.16$ & 0.48 \\
\hline BMI $\left(\mathrm{kg} / \mathrm{m}^{2}\right)$ & $24.40 \pm 6.26$ & $25.13 \pm 6.95$ & $24.99 \pm 2.95$ & $25.29 \pm 5.72$ & 0.46 \\
\hline WHR & $0.73 \pm 0.04$ & $0.75 \pm 0.07$ & $0.74 \pm 0.06$ & $0.76 \pm 0.06$ & 0.27 \\
\hline (\%) Body fat & $36.56 \pm 6.30$ & $36.62 \pm 8.68$ & $35.46 \pm 4.13$ & $37.94 \pm 6.21$ & 0.46 \\
\hline ALP (IU/L) & $134.00 \pm 32.48$ & $135.90 \pm 64.62$ & $173.30 \pm 44.90$ & $162.80 \pm 51.52$ & 0.15 \\
\hline 25OH-D (ng/ml) & $16.50 \pm 9.61$ & $25.10 \pm 11.78$ & $24.30 \pm 18.05$ & $15.70 \pm 5.49$ & 0.03 \\
\hline Right hip BMD (T-score) & $-1.07 \pm 0.43$ & $-0.57 \pm 0.49$ & $-1.25 \pm 0.58$ & $-1.18 \pm 0.54$ & 0.001 \\
\hline Left hip BMD (T-score) & $-2.56 \pm 0.18$ & $-2.72 \pm 0.18$ & $-2.72 \pm 0.20$ & $-2.42 \pm 0.28$ & 0.01 \\
\hline Lumbar spine (L2-L4) BMD (T-score) & $0.31 \pm 0.81-$ & $0.48 \pm 0.88-$ & $0.32 \pm 0.81-$ & $0.11 \pm 0.69-$ & 0.01 \\
\hline
\end{tabular}

Standard deviation (SD); body mass index (BMI); waist to hip ratio (WHR); alkaline phosphatase (ALP); 25-hydroxyvitamin D (25OH-D); bone mineral density (BMD); concurrent training-milk consumption $(C T+M C)$; concurrent training $(C T)$; milk consumption (MC); Control (C) 



Fig. 2 Changes in ALP (a), 25OH-D (b), right hip BMD (c), left hip BMD (d) and lumbar spine (e) following 10 weeks training intervention (mean \pm SD). *: denotes significant differences between baseline and post training values ( $p \leq 0.05)$. Standard deviation (SD); alkaline phosphatase (ALP); 25-hydroxyvitamin D (25OH-D); bone mineral density (BMD); concurrent training-milk consumption (CT + MC); concurrent training (CT); milk consumption (MC); Control (C)

significant compared to milk consumers and control groups $(p<0.001, p<0.001$; respectively), while there was not significant compared to the concurrent training group $(p=0.11)$. Moreover, left hip and lumbar spine BMD changes in concurrent training group were significant compared to milk consumers and control group (left hip: $p<0.001, p=0.006$; lumbar spine: $p<0.001, p$ $<0.001$; respectively); while, changes in the right hip BMD and ALP between concurrent training with milk consumer and control groups were not significant (right hip: $p=0.73, p=0.20$; ALP: $p=0.24, p=0.07$; respectively) (Table 2).

\section{Discussion}

This study examined the effects of concurrent training and milk consumption on some indices of BMD in women with osteoporosis. The results showed that concurrent training and milk combination had a greater impact on BMD in young women with osteoporosis than the mere consumption of milk or concurrent training.

The ground reaction force and strain force caused by various muscle contractions during exercise can cause a certain amount of stimulation for the bone, and these mechanical stresses can improve the strength and biochemical properties of the bone. Proper mechanical stresses can cause bone formation, increase BMD, and prevent development of osteoporosis [23]. The results of the review conducted by Yuan et al. [23] showed that exercise improves BMD, bone mass, bone strength and bone mechanical properties. Physical activity seems to directly and indirectly affect all bone cells and affects many aspects of bone remodeling. Evidences suggest that exercise induces bone formation by stimulating mesenchymal stem cells, osteogenic differentiation and osteoblast and osteocyte activities; also, the exercise mechanical load and the Wnt-Catenin and the bone 
Table 2 Results of ANCOVA and post hoc test

\begin{tabular}{|c|c|c|c|c|c|}
\hline Characteristic & Groups & & Mean difference & Standard error & $P$ \\
\hline \multirow[t]{5}{*}{ ALP (IU/L) } & $C T+M C$ & $\mathrm{CT}$ & 4.85 & 14.33 & 0.73 \\
\hline & & $M C$ & 22.69 & 15.03 & 0.14 \\
\hline & & C & 32.27 & 14.71 & $0.03^{*}$ \\
\hline & $\mathrm{CT}$ & $\mathrm{MC}$ & 17.83 & 15.00 & 0.24 \\
\hline & & C & 27.41 & 14.69 & 0.07 \\
\hline \multirow[t]{5}{*}{ 25OH-D (ng/ml) } & $C T+M C$ & $\mathrm{CT}$ & 8.17 & 3.94 & $0.04^{*}$ \\
\hline & & $M C$ & 10.75 & 3.86 & $0.009^{*}$ \\
\hline & & $C$ & 18.10 & 3.70 & $0.001^{*}<$ \\
\hline & $\mathrm{CT}$ & $M C$ & 2.58 & 3.70 & 0.49 \\
\hline & & C & 9.93 & 4.00 & $0.01^{*}$ \\
\hline \multirow[t]{5}{*}{ Right hip BMD (T-score) } & $C T+M C$ & $\mathrm{CT}$ & 0.36 & 0.09 & $0.001^{*}$ \\
\hline & & $M C$ & 0.33 & 0.09 & $0.001^{*}$ \\
\hline & & C & 0.50 & 0.08 & $0.001^{*}<$ \\
\hline & $\mathrm{CT}$ & $M C$ & -0.03 & 0.10 & 0.73 \\
\hline & & C & 0.13 & 0.10 & 0.20 \\
\hline \multirow[t]{5}{*}{ Left hip BMD (T-score) } & $C T+M C$ & $\mathrm{CT}$ & 0.13 & 0.08 & 0.11 \\
\hline & & $\mathrm{MC}$ & 0.44 & 0.08 & $0.001^{*}<$ \\
\hline & & $C$ & 0.38 & 0.08 & $0.001^{*}<$ \\
\hline & $C T$ & $M C$ & 0.30 & 0.08 & $0.001^{*}<$ \\
\hline & & $C$ & 0.25 & 0.08 & $0.006^{*}$ \\
\hline \multirow[t]{5}{*}{ Lumbar spine (L2-L4) BMD (T-score) } & $C T+M C$ & $C T$ & -0.12 & 0.05 & $0.01^{*}$ \\
\hline & & $M C$ & 0.29 & 0.04 & $0.001^{*}<$ \\
\hline & & $C$ & 0.31 & 0.05 & $0.001^{*}<$ \\
\hline & $\mathrm{CT}$ & $M C$ & 0.41 & 0.05 & $0.001^{*}<$ \\
\hline & & $C$ & 0.44 & 0.06 & $0.001^{*}<$ \\
\hline
\end{tabular}

Alkaline phosphatase (ALP); 25-hydroxyvitamin D (25OH-D); bone mineral density (BMD); concurrent training-milk consumption (CT + MC); concurrent training (CT); milk consumption (MC); Control (C). ${ }^{*}$ denotes significant differences between groups at post training $(p \leq 0.05)$

morphogenetic proteins pathway play an important role. In addition, the results indicated an increase in osteogenic differentiation and bone formation due to changes in levels of hormones such as parathyroid hormone $(\mathrm{PTH})$, estrogen and prostaglandin E2 in exercise. Of course, the intensity and type of exercise can have different effects on individuals [23].

A few studies have investigated the impact of concurrent training on BMD while the main focus has been on investigating aerobic and resistance activities separately. The effect of separate aerobic exercise on BMD in adults is weak. The evidence for the effectiveness of this type of training to deal with age-related bone loss has been controversial [24, 25]. The results of Silverman et al. [26] showed that the bone density in femoral neck increased by $2 \%$ in postmenopausal women after 24 weeks of training in the form of walking. Aerobic training protocol usually includes walking without lateral and twisting movements which is not enough for bone density. In the ideal condition, running and walking can be effective in limiting the bone density reduction in elderly; anyway, training with average to high intensity is controversial. Low intensity aerobic training such as walking put lower pressure on the body compared to running; also, it may lead to weak stimulation of osteogenic [27]. Alghadir et al. [28] suggested that moderate-intensity aerobic exercises may protect bone and cartilage by regulating the body trace elements that are involved in the bone matrix biosynthesis and inhibit the bone resorption process through the proposed anti-free radical mechanism. Also, a study by Wen et al. [29] stated that short-term group-based step aerobics exercises are beneficial for bone metabolism and reduces bone resorption activity.

Regarding the effects of resistance training, the results of Mosti et al. [30] showed that after 12 weeks of strength training in postmenopausal women diagnosed with osteopenia and osteoporosis, 1RM and the rate of force development training group improved and the bone density in the lumbar spine and femoral neck increased for 2.9 and $4.9 \%$, respectively. The serum type 1 collagen amino-terminal propeptide (P1NP)/type 1 collagen $\mathrm{C}$ breakdown products 
(CTX) tend to increase but not significantly, which represents stimulate bone formation. The results of Petersen et al. [31] suggested that a low-load strength exercise program with high repetitions can be an effective way to improve bone mass in adults. In addition, Watson et al. [32] suggested increased bone strength indices in postmenopausal women with low bone mass after high-intensity resistance exercise and impact training.

Contrary to these studies, the results of Almstedt et al. [18] showed that 24 weeks of resistance training is effective in increasing BMD in healthy young men (2. 7-7.7\% increase), but for women, the training program did not show a significant increase in BMD (changes in BMD 0. 8-1.5\%). Singh et al. [33] in his premenopausal study found that strength training in a training course of more than 9 months did not lead to significant changes in the total body BMD. Nakata et al. [34] concluded that resistance training during weight loss had no effect on BMD in premenopausal women with overweight.

Considering the dissimilarity of women responses in different ages (probably due to the deterioration of the ability of bone cells to receive physical signals or inability to respond) and the fact that estrogen deprivation is associated with increased severity of reconstruction [35], skeletal response to training is related to age. On the whole, the effect of mechanical loading forces on osteogenic reduces with aging and it seems that there is a gradual reduction of bone sensitivity to chemical and physical signals [36].

The results showed positive effects of combined concurrent training and milk consumption on BMD in young women with osteoporosis compared to consumption of milk or concurrent training, separately. In line with that, we can refer to Lester et al. [37] study which examined the effect of 8 weeks of aerobic, resistance and concurrent training on the bone biomarkers responses in inactive young women. Their results showed that the effect of osteogenic activity indices on biomarkers of bone formation (bone-specific ALP and osteocalcin) increased in the resistance and combination group. However, biomarkers of bone resorption (tartrate-resistant acid phosphatase and deoxypyridinoline) have declined in the resistance group and increased in the combination group after exercise. In the aerobic and combination groups little changes in volume and BMD were observed [37]. Moreover, Marques et al. [17] investigated the effects of aerobic and resistance training and the results showed that after eight months of training (three sessions per week), only resistance group demonstrated an increase in BMD in the trochanter (2.9\%) and total hip (1.5\%). They stated that both aerobic and resistance groups improved their balance but there were no significant changes in serum osteoprotegerin (OPG) and receptor activator of nuclear factor kappa B ligand (RANKL) levels. Based on the previous studies and the present study, it can be argued that the combination of aerobic and resistance training (concurrent training) had the greatest effect on BMD and may be more beneficial than doing aerobics or resistance training alone to prevent osteoporosis in young people.

Calcium is an essential nutrient and important for bone health, peak bone mass, prevention and treatment of osteoporosis throughout life [38]. The main mechanisms involved in controlling bone regeneration and calcium homeostasis include changes in plasma PTH, calcitriol, calcium and phosphate, bone regeneration markers due to hypoparathyroidism and hyperparathyroidism, renal failure, daily PTH 1-34 administration, and RANKL inhibition [39]. Regarding the milk consumption and calcium rich resources, we can refer to Dionyssiotis et al. [40] study, who argued that physical activity and appropriate intake of calcium have beneficial effects on bone mass. They stated that women who did regular activity and calcium intake were more than $800 \mathrm{mg}$ per day, had higher T-score than other groups who did not take calcium.

A study by Laird et al. [41] showed that high levels of yogurt are associated with an increase in BMD and exercise performance score. In addition, they first showed that with increasing consumption of yogurt, significantly decreased the odds of being characterized as osteopenic or osteoporotic in women and as osteoporotic in men. They linked this association to natural content of yogurt (yogurt naturally contains minerals and vitamins needed to develop bone density). Chen et al. [42] found that high calcium milk powder supplementation to delay and slow down bone loss was better than medium and low calcium supplementation in healthy postmenopausal women. A supplement containing $300 \mathrm{mg}$ per day of calcium cannot reduce bone loss in the lumbar spine and greater Trochanter, but $600-900 \mathrm{mg}$ per day can be beneficial. Also, Ikedo et al. [43] on Long-distance running women showed that taking vitamin $\mathrm{D}$ supplementation and low-fat milk for 6 months improved bone metabolism by maintaining the concentration of 25OH-D and decreasing concentration of PTH and reducing inflammatory cytokines. Furthermore, Rajatanavin et al. [38] stated that calcium supplementation of $500 \mathrm{mg}$ per day can reduce bone turnover and decrease bone mass in older women.

Contrary to these studies, the meta-analysis by Tai et al. [44] suggested that increasing calcium intakes in daily food sources or by taking calcium supplements causes a slight increase in BMD and is unlikely to significantly reduce the risk of pancreatitis. Also, meta-analysis by Bolland et al. [45] indicated that the calcium intake is unrelated to bone fracture risk, and also argued that clinical evidence that increasing calcium intakes from food sources prevents fractures is weak and 
contradictory. The results of a study by Hirota et al. [46] demonstrated that lumbar spine BMD decreased after 4 months of diet compared to the initial value in both control and milk consumption groups. They suggested that muscle mass in milk consumption group was associated with changes in BMD of the lumbar spine and in subjects who had the greatest increase muscle mass, no reduction was observed in lumbar spine BMD.

Clinical trials have shown that calcium supplementation with or without vitamin D can reduce secondary hyperparathyroidism, slow down bone turnover, increase areal $\mathrm{BMD}$, or slow down bone loss [6-8]. The beneficial effects of supplementation on bone density result from a decrease in bone remodeling space which lead to a decrease in the number of remodeling sites activated of bone, leading to reduction in bone resorption [47]. Calcium supplementation has an acute antiresorptive effect on bones which set bone reconstruction in a regular basis to maintain bone density or slow loss of the BMD, preserve cortical thickness by reducing endocortical resorption, and perhaps reduce the increase in intracortical porosity and/ or improve bone mineralization [47]. Based on the results of the previous and the present study, it seems that milk consumption (as a rich source of calcium) may have beneficial effects on bone mass of young people and prevent osteoporosis with aging. Moreover, combining milk consumption with concurrent training (aerobic-resistance) may increase its potential.

\section{Conclusions}

The results of the present study showed that combining concurrent training with milk consumption on the BMD of young women with osteoporosis is more beneficial compared to separate milk consumption or training. Therefore, it seems that doing concurrent training and consuming milk can be used as an effective way to improve BMD in young women with diagnosed osteoporosis.

\section{Abbreviations}

25OH-D: 25-hydroxyvitamin D; ALP: Alkaline phosphatase; BMD: Bone mineral density; BMI: Body mass index; C: Control; CT + MC: Concurrent training-milk consumption; CT: Concurrent training; MC: Milk consumption; CTX: Type 1 collagen $C$ breakdown products; DEXA: Dual-energy $\mathrm{X}$-ray absorptiometry; HRmax: Heart rate maximum; IOM: Institute of medicine;

OPG: Osteoprotegerin; P1NP: Type 1 collagen amino-terminal propeptide; PTH: Parathyroid hormone; RANKL: Receptor activator of nuclear factor kappa B ligand; RM: Repetition maximum; WHO: World health organization; WHR: Waist to hip ratio

\section{Acknowledgements}

The authors hereby declare their gratitude to all those who participated as subjects in this study.

\section{Funding}

There was no any funding regarding this study.

\section{Availability of data and materials}

The datasets during and/or analysed during the current study available from the corresponding author on reasonable request.

\section{Authors' contributions}

$H$. A made substantial contributions to conception and design of research. $H$. A, M. S and E. E had fundamental roles in acquisition of data, analysis and interpretation of data. All authors read and approved the final manuscript.

\section{Ethics approval and consent to participate}

The participants signed an informed consent before the start of the study. The study was conducted in accordance with the Declaration of Helsinki and was approved by the ethics committee of the University.

\section{Consent for publication}

Not applicable.

\section{Competing interests}

The authors declare that they have no competing interests.

\section{Publisher's Note}

Springer Nature remains neutral with regard to jurisdictional claims in published maps and institutional affiliations.

\section{Author details}

${ }^{1}$ Department of Exercise Physiology, Faculty of Sport Sciences, University of Guilan, Rasht, Iran. Department of Exercise Physiology, Islamic Azad University, Rasht Branch, Rasht, Iran. ${ }^{3}$ Department of Exercise Physiology, Faculty of Sport Sciences, University of Guilan, Rasht, Iran.

Received: 18 March 2018 Accepted: 27 November 2018

Published online: 17 December 2018

\section{References}

1. Kumar A, Mittal S, Orito S, Ishitani K, Ohta H. Impact of dietary intake, education, and physical activity on bone mineral density among north Indian women. J Bone Min Metab. 2010;28(2):192-201.

2. El Hage R, Baddoura R. Anthropometric predictors of geometric indices of hip bone strength in a group of Lebanese postmenopausal women. J Clin Densitom. 2012:15(2):191-7.

3. Sambrook PC. Cooper. Osteoporosis Lancet. 2006;367:2010-8.

4. Prentice AM. Dairy products in global public health. Am J Clin Nutr. 2014; 99(5):1212-6.

5. Heaney RP. Calcium, dairy products and osteoporosis. J Am Coll Nutr. 2000; 19:83S-995.

6. Zhu K, Devine A, Dick IM, Wilson SG, Prince RL. Effects of calcium and vitamin D supplementation on hip bone mineral density and calciumrelated analytes in elderly ambulatory Australian women: a five-year randomized controlled trial. J Clin Endocrinol Metab. 2008;93:743-9.

7. Jackson RD, LaCroix AZ, Gass M, Wallace RB, Robbins J, Lewis CE, Bonds DE. Calcium plus vitamin D supplementation and the risk of fractures. N Engl J Med. 2006:354:669-83.

8. Daly RM, Bass S, Nowson C. Long-term effects of calciumvitamin-D3-fortified milk on bone geometry and strength in older men. Bone. 2006;39:946-53.

9. Maurel DB, Boisseau N, Ingrand I, Dolleans E, Benhamou CL, Jaffre C. Combined effects of chronic alcohol consumption and physical activity on bone health: study in a rat model. Eur J Appl Physiol. 2011;111(12):2931-40.

10. Nichols JF, Rauh MJ, Barrack MT, Barkai HS. Bone mineral density in female high school athletes: interactions of menstrual function and type of mechanical loading. Bone. 2007;41(3):371-7.

11. Novotny SA, Warren GL, Hamrick MW. Aging and the muscle-bone relationship. Physiology. 2015:30(1):8-16.

12. Polidoulis I, Beyene J, Cheung AM. The effect of exercise on PQCT parameters of bone structure \& strength in postmenopausal women-a systematic review \& meta-analysis of randomized controlled trials. Osteoporos Int. 2012;23:39-51.

13. Bemben DA, Bemben MG. Dose-response effect of 40 week of resistance training on bone mineral density in older adults. International osteoporosis foundation \& national foundation. 2011:22:179-86.

14. White KM, Bauer SJ, Hartz KK, Baldridge M. Changes in body composition with yogurt consumption during resistance training in women. Int J Sport Nutr. 2009;19(1):18

15. Warden SJ, Fuchs RK, Turner CH. Steps for targeting exercise towards the skeleton to increase bone strength. Eur Medicophys. 2004;40:223. 
16. Kemmler W, Engelke K, Lauber D, Weineck J, Hensen J, Kalender WA. Exercise effects on fitness and bone mineral density in early postmenopausal women: 1-year EFOPS results. Med Sci Sports Exerc. 2002 34:2115.

17. Marques EA, Wanderley F, Machado L, Sousa F, Viana JL, Moreira-Gonçalves $D$, Carvalho J. Effects of resistance and aerobic exercise on physical function, bone mineral density, OPG and RANKL in older women. Exp Gerontol. 2011; 46(7):524-32.

18. Almstedt HC, Canepa JA, Ramirez DA, Shoepe TC. Changes in bone mineral density in response to 24 weeks of resistance training in college-age men and women. J Strength Cond Res. 2011;25(4):1098-103.

19. Jackson AS, Pollock ML. Generalized equations for predicting body density of men. Br J Nutr. 1978:40(03):497-504.

20. Brozek J, Grande F, Anderson JT, Keys A. Densitometric analysis of body composition: revision of some quantitative assumptions. Ann N Y Acad Sci. 1963;110:113-40.

21. IOM (Institute of Medicine). Dietary reference intakes for calcium and vitamin D. Washington, DC: National Academies Press; 2011.

22. WHO. Scientific Group on Prevention, Management of Osteoporosis, \& World Health Organization. In: Prevention and management of osteoporosis: report of a WHO scientific Group World Health Organization, vol. 921; 2003.

23. Yuan $Y$, Chen $X$, Zhang L, Wu J, Guo J, Zou D, Zou J. The roles of exercise in bone remodeling and in prevention and treatment of osteoporosis. Prog Biophys Mol Biol. 2016;122(2):122-30.

24. Bonaiuti D, Shea B, lovine R, Negrini S, Welch V, Kemper HH, Cranney A. Exercise for preventing and treating osteoporosis in postmenopausal women. Cochrane Libr. 2002.

25. Brooke-Wavell $K$, Jones PR, Hardman AE, Tsuritan Yamada Y. Commencing, continuing and stopping brisk walking: effects on bone mineral density, quantitative ultrasound of bone and markers of bone metabolism in postmenopausal women. Osteoporos Int. 2001;12:581-7.

26. Silverman NE, Nicklas BJ, Ryan AS. Addition of aerobic exercise to a weight loss programme increases BMD, with an associated reduction in inflammation in overweight postmenopausal women. Calcif Tissue Int. 2009;84:257-65.

27. Liu PY, Brummel-Smith K, Ilich JZ. Aerobic exercise and whole-body vibration in offsetting bone loss in older adults. J Aging Res. 2011;2011: 379674

28. Alghadir AH, Gabr SA, Al-Eisa ES, Alghadir MH. Correlation between bone mineral density and serum trace elements in response to supervised aerobic training in older adults. Clin Interv Aging. 2016;11:265.

29. Wen HJ, Huang TH, Li TL, Chong PN, Ang BS. Effects of short-term step aerobics exercise on bone metabolism and functional fitness in postmenopausal women with low bone mass. Osteoporos Int. 2017;28(2): 539-47.

30. Mosti MP, Kaehler N, Stunes AK, Hoff J, Syversen U. Maximal strength training in postmenopausal women with osteoporosis or osteopenia. J Strength Cond Res. 2013;27(10):2879-86.

31. Petersen BA, Hastings B, Gottschall JS. Low load, high repetition resistance training program increases bone mineral density in untrained adults. J Sport Med Phys Fit. 2017;57(1-2):70-6.

32. Watson SL, Weeks BK, Weis LJ, Harding AT, Horan SA, Beck BR. Highintensity resistance and impact training improves bone mineral density and physical function in postmenopausal women with osteopenia and osteoporosis: the LIFTMOR randomized controlled trial. J Bone Miner Res. 2017;33(2):211-20

33. Singh JA, Schmitz KH, Petit MA. Effect of resistance exercise on bone mineral density in premenopausal women. Joint Bone Spine. 2009;76: 273-80.

34. Nakata Y, Ohkawara K, Lee DJ, Okura T, Tanaka K. Effects of additional resistance training during diet-induced weight loss on bone mineral density in overweight premenopausal women. J Bone Miner Metab. 2008;26:172-7.

35. Lanyon L, Skerry T. Postmenopausal osteoporosis as a failure of bone's adaptation to functional loading: a hypothesis. J Bone Miner Res. 2001;16: 1937-47.

36. Rubin CT, Bain SD, McLeod KJ. Suppression of the osteogenic response in the aging skeleton. Calcif Tissue Int. 1992;50:306-13.

37. Lester ME, Urso ML, Evans RK, Pierce JR, Spiering BA, Maresh CM, Nindl BC. Influence of exercise mode and osteogenic index on bone biomarker responses during short-term physical training. Bone. 2009;45(4):768-76.
38. Rajatanavin R, Chailurkit L, Saetung S, Thakkinstian A, Nimitphong H. The efficacy of calcium supplementation alone in elderly Thai women over a 2-year period: a randomized controlled trial. Osteoporos Int. 2013;24(11):2871-7.

39. Peterson MC, Riggs MM. A physiologically based mathematical model of integrated calcium homeostasis and bone remodeling. Bone. 2010;46(1):49-63.

40. Dionyssiotis Y, Paspati I, Trovas G, Galanos A, Lyritis GP. Association of physical exercise and calcium intake with bone mass measured by quantitative ultrasound. BMC Wom Health. 2010;10(1):1.

41. Laird E, Molloy AM, McNulty H, Ward M, McCarroll K, Hoey L, Casey MC. Greater yogurt consumption is associated with increased bone mineral density and physical function in older adults. Osteoporos Int. 2017:1-11.

42. Chen Y, Xiao Y, Xie B, Zhang Q, Ma X, Li N, Zhang Q. Effect of milk powder supplementation with different calcium contents on bone mineral density of postmenopausal women in northern China: a randomized controlled double-blind trial. Calcif Tissue Int. 2016;98(1):60-6.

43. Ikedo A, Arimitsu T, Kurihara T, Ebi K, Fujita S. The effect of ongoing vitamin $\mathrm{D}$ and low-fat milk intake on bone metabolism in female high-school endurance runners. J Clin Med Res. 2017;10(1):13-21.

44. Tai V, Leung W, Grey A, Reid IR, Bolland MJ. Calcium intake and bone mineral density: systematic review and meta-analysis. Br Med J. 2015; 351:h4183.

45. Bolland MJ, Leung W, Tai V, Bastin S, Gamble GD, Grey A, Reid IR. Calcium intake and risk of fracture: systematic review. Br Med J. 2015;351:h4580.

46. Hirota T, Kawasaki I, Hirota K. Effects of high calcium and vitamin D diets on changes in body fat, lean mass, and bone mineral density by self-controlled dieting for 4 months in young Asian women. In: Nutritional influences on bone health. Springer London; 2011. p. 73-9.

47. Daly RM, Kukuljan S. Independent and combined effects of exercise and calcium on bone structural and material properties in older adults. In: Nutritional influences on bone health. London: Springer; 2011. p. 51-8.

Ready to submit your research? Choose BMC and benefit from:

- fast, convenient online submission

- thorough peer review by experienced researchers in your field

- rapid publication on acceptance

- support for research data, including large and complex data types

- gold Open Access which fosters wider collaboration and increased citations

- maximum visibility for your research: over $100 \mathrm{M}$ website views per year

At $\mathrm{BMC}$, research is always in progress.

Learn more biomedcentral.com/submissions 